\title{
Demonstration of Nitride-on-Phosphide Hybrid Tandem Solar Cells by Using Surface-Activated Bonding
}

\author{
Naoteru Shigekawa ${ }^{1}$, Jianbo Liang ${ }^{1}$, and Noriyuki Watanabe ${ }^{2}$ \\ ${ }^{1}$ Osaka City University, 3-3-138 Sugimoto, Sumiyoshi, Osaka 558-8585, Japan \\ ${ }^{2}$ NTT Photonics Laboratories, Nippon Telegraph and Telephone Corporation, Atsugi, Kanagawa 243-0198, Japan
}

\begin{abstract}
Group-III nitride-on-phosphide hybrid tandem solar cells were fabricated using surface-activated bonding. The bottom surface of nitride top cells grown on GaN substrates was bonded on the top surface of InGaP-based bottom cells grown on $n$-GaAs substrates. Their tandem-cell operation was successfully demonstrated by confirming that the open-circuit voltage $\left(V_{\mathrm{OC}}\right)$ of tandem cells was enhanced. It was also found that the electrical properties of the bonding interface do not induce fatal effects on the performance of the tandem cells.
\end{abstract}

Index Terms - surface-activated bonding, tandem, InGaP, InGaN, GaN substrate

\section{INTRODUCTION}

Compound-semiconductor-based tandem (multi junction) solar cells, which have reportedly produced high conversion efficiencies in comparison with other solar cell structures [1], are promising as practical candidates for next-generation solar cells. Triple junction cells employing InGaP subcells as the top cells have reportedly produced conversion efficiencies $>30 \%$ [2], [3], [4].

The strategy for realizing higher efficiencies in the tandem cells is to slice the solar spectrum into a larger number $(>$ 3) of parts and absorb the respective parts by using subcells with optimized bandgaps. Top cells with larger bandgapsbandgaps higher than that for phosphides - are, consequently, likely to be required for proceeding along this scenario. GroupIII nitride (InGaN, AlGaN, InAlN)/phosphide subcell stacks are assumed to play an important role in this framework since the bandgap of nitrides is varied between $0.7(\mathrm{InN})$ and 6.2 (AlN) eV [5]. Possibility of nitrides as constituent of solar cells has been widely explored [5], [6], [7], [8], [9], [10], [11]. The tandem cells composed of GaN and (111) Si subcells were monolithically fabricated by using RFMBE [7].

Given that the typical crystal structures of nitride (wurtzite) and phosphide (zincblende) are different from each other, the mechanical-stacking (hybrid) approaches [12], [13], [14] must be used for realizing the nitride-on-phosphide subcell stacks. The surface-activated bonding (SAB), in which the native oxide layers formed on surfaces of substrates are removed by Ar beam irradiation prior to bonding [15], [16], is one of the promising methods for the hybrid tandem approach. The present authors previously fabricated $\mathrm{Si} / \mathrm{Si}, \mathrm{Si} / \mathrm{GaN}$, and $\mathrm{Si} / \mathrm{GaAs}$ junctions by using SAB and reported their structural and electrical characteristics [17], [18], [19]. The application of $\mathrm{SAB}$ to nitride/Si tandem cells shall be reported elsewhere [20].

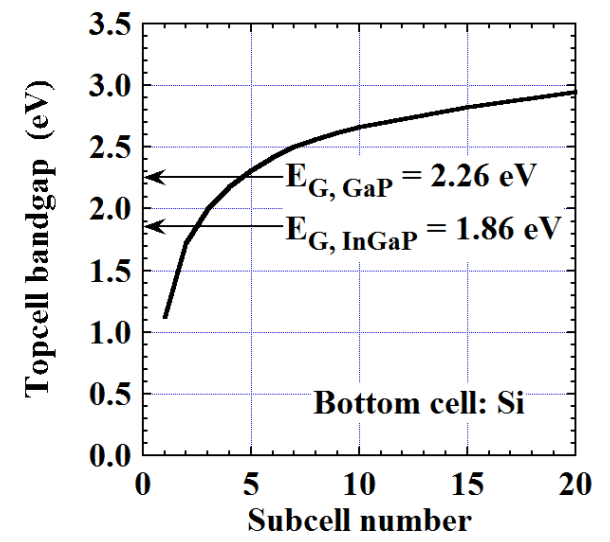

Fig. 1. Relationship between the optimum bandgap of the top cell and the number of subcells in case of Si-based bottom cells.

In this work, we first quantitatively confirm the significance of nitride materials for wide-gap subcells in the context of the current matching condition. We next discuss the fabrication and characterization of SAB-based nitride (InGaN/GaN multi quantum wells (MQWs))/phosphide (InGaP) tandem cells and examine the applicability of the SAB for the tandem approach.

\section{RESUlts AND Discussion}

\section{A. Optimum bandgaps of top cells}

The optimum bandgaps for the respective subcells in case of Si-based bottom cells were estimated with reference to the requirement that the equal number of photons from the solar light are absorbed by each subcell. Figure. 1 shows the relationship between the estimated bandgap of the top cell and the number of subcells $N$ under the air mass $1.5 \mathrm{G}$ illumination. Bandgaps of InGaP lattice-matched to GaAs and $\mathrm{GaP}$, which are 1.86 and $2.26 \mathrm{eV}$, respectively, are also shown in this figure. The bandgap of the top cell is larger than $2.3 \mathrm{eV}$ for $N \geqq 5$, which means that materials with bandgaps larger than those of group-III phosphides are needed in composing tandem cells of such an extremely large number of subcells. The nitride-on-phosphide subcell stacks are, consequently, expected to play an important role in such situation.

\section{B. Sample Preparation}

On $n$-type (0001) GaN substrates with the carrier concentration of $\sim 10^{18} \mathrm{~cm}^{-3}$, we grew $100 \mathrm{~nm}$-thick $n$-doped 
GaN buffer layers $\left(\sim 5 \times 10^{18} \mathrm{~cm}^{-3}\right)$, undoped 10 pairs of InGaN/GaN MQWs, and $p$-doped emitter/contact layers in this sequence. By using Xray-diffraction analyses, the thicknesses of InGaN well layers and $\mathrm{GaN}$ barrier layers in MQWs were found to be 3.4 and $5.8 \mathrm{~nm}$, respectively. Furthermore the InN mole fraction of InGaN well layers was estimated to be 0.14 . Details of growth and characterization of the layer structure were previously reported [21]. We made nitride cells with emitter and base contacts on the contact layers and the surfaces of the $n$-GaN buffer layers exposed by mesa etching. The area of the mesa was 1-mm or 2-mm square. By polishing the bottom surfaces of substrates, their averaged roughness was improved from $170 \mathrm{~nm}$ (prior to polishing) to $0.33 \mathrm{~nm}$ (after polishing) as is shown in Fig. 2(a). We then diced the GaN substrates into $1.2 \mathrm{~cm}^{2}$ chips.

The layers for lattice-matched InGaP cells was prepared by the MOCVD growth of $p^{+}$-doped GaAs contact layer, $p$-doped InAlP window layer, $p$-doped InGaP emitter layer, $n$-doped $\mathrm{InGaP}$ absorption layer, $n^{+}$-doped $\mathrm{InGaP}$ layer, and $n^{+}$-doped GaAs layer on $n$-type (100) GaAs substrates (from top to bottom). The doping concentration of the top $p^{+}-\mathrm{GaAs}$ contact layer was as high as $\sim 1 \times 10^{19} \mathrm{~cm}^{-3}$. The electrical contacts on the bottom surfaces were obtained by evaporating $\mathrm{AuGe} / \mathrm{Ni} / \mathrm{Ti} / \mathrm{Au}$.

Thank to their smoothed bottom surfaces, the $n$-type $\mathrm{GaN}$ substrates were successfully bonded to the top $p^{+}$-doped GaAs layers of InGaP cells, so that the nitride-on-phosphide tandem cells were composed. The background atmospheric pressure in the bonding chamber prior to Ar beam irradiation was $\sim 10^{-6} \mathrm{~Pa}$. The bonding pressure was $\sim 10 \mathrm{MPa}$. The schematic cross section of the tandem cells and their top view are shown in Figs. 2(b) and (c), respectively. Note that the characteristics of the tandem cells and the constituent nitride cells are independently measured for the respective nitride mesas. In addition, we independently fabricated InGaP single junction cells with the same layer structures as those employed for the bottom cells for comparison.

\section{Cell Characterization}

The current-voltage $(I-V)$ characteristics of the respective cells were measured by using an in-house solar simulator with the condition of air mass (AM) $1.5 \mathrm{G}$ and one sun at room temperature. Figure 3(a) compares $I-V$ characteristics of the tandem cell and the constituent nitride top cell. The opencircuit voltage $\left(V_{\mathrm{OC}}\right)$ and the short-circuit current $\left(J_{\mathrm{SC}}\right)$ of nitride cell are $0.94 \mathrm{~V}$ and $0.17 \mathrm{~mA} / \mathrm{cm}^{2}$, respectively. Its fill factor and the conversion efficiency are $33 \%$ and $0.05 \%$, respectively. $V_{\mathrm{OC}}$ and $J_{\mathrm{SC}}$ of the tandem cell are $1.84 \mathrm{~V}$ and $0.19 \mathrm{~mA} / \mathrm{cm}^{2}$. The fill factor is $50 \%$ so that the conversion efficiency is $0.17 \%$. In Fig. 3(b) is shown the relationship between $V_{\mathrm{OC}}$ of tandem cells and that of nitride top cells measured for several nitride mesas. The difference in $V_{\mathrm{OC}}$ $\Delta V_{\mathrm{OC}}$ was estimated to be $0.92 \mathrm{~V}$ by the least-square fitting.

The $I-V$ characteristics of the InGaP single junction cell are shown in Fig. 3(c). Its $J_{\mathrm{SC}}, V_{\mathrm{OC}}$, fill factor, and conversion efficiency are $7.42 \mathrm{~mA} / \mathrm{cm}^{2}, 1.35 \mathrm{~V}, 77.1 \%$, and
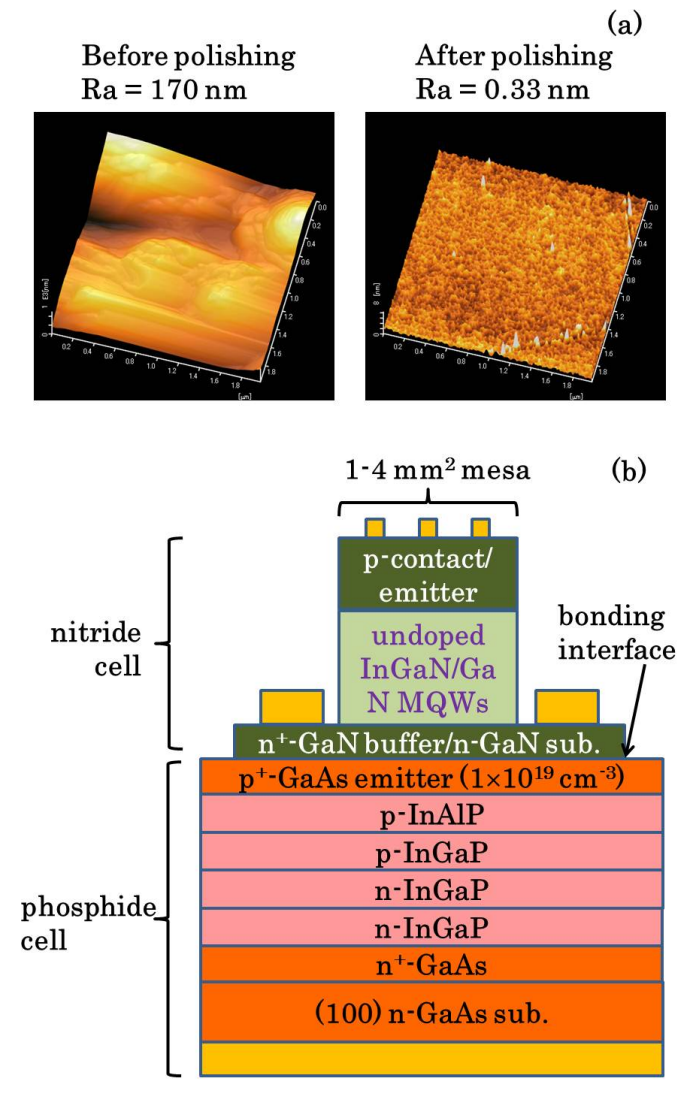

(c)

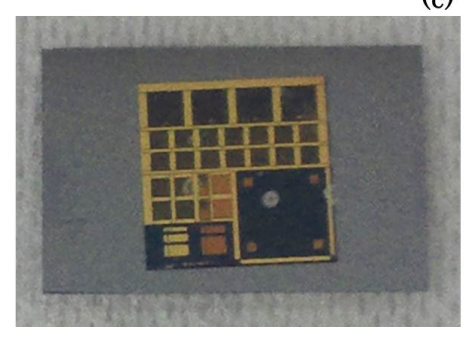

Fig. 2. (a) AFM images of the pre- and post-polished bottom surfaces of $\mathrm{GaN}$ substrates on which the nitride top cells were formed. (b) The schematic cross section of nitride-on-phosphide tandem cells. (c) A photo (top view) of fabricated tandem cells.

$7.71 \%$, respectively. These results clearly show that $V_{\mathrm{OC}}$ was enhanced by stacking the nitride and InGaP cells in accordance with the expectation whilst the performance of the tandem cells was limited by that of the nitride cells.

Figure 4 shows the $I-V$ characteristics measured between the base contacts of nitride cells and InGaP cells with the base contacts of $\mathrm{InGaP}$ cells grounded. The entire cell was illuminated during the measurement. It is found that there occurs a photocurrent of $2.12 \mathrm{~mA} / \mathrm{cm}^{2}$ flowing across the $n$ $\mathrm{GaAs} / p^{+}$-GaAs interface at zero bias voltage, which is larger than $J_{\mathrm{SC}}$ of tandem cells $\left(\approx 0.2 \mathrm{~mA} / \mathrm{cm}^{2}\right)$ by ten times.

We find that $\Delta V_{\mathrm{OC}}(0.92 \mathrm{~V}$ as is seen from Fig. 3(b)) is lower than $V_{\mathrm{OC}}$ of the InGaP single junction cell $(1.35 \mathrm{~V})$. The disagreement is possibly explained by a potential barrier at the 


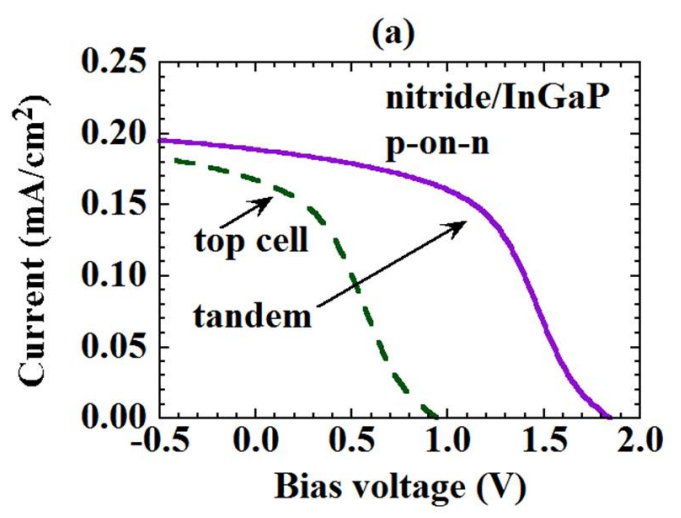

\begin{tabular}{|l|c|c|}
\hline & top cell & tandem cell \\
\hline$V_{\text {OC }}(\mathbf{V})$ & 0.94 & 1.84 \\
\hline$J_{\text {SC }}\left(\mathbf{m A} / \mathbf{c m}^{2}\right)$ & 0.17 & 0.19 \\
\hline FF $(\%)$ & 33 & 50 \\
\hline$\eta(\%)$ & 0.05 & 0.17 \\
\hline
\end{tabular}
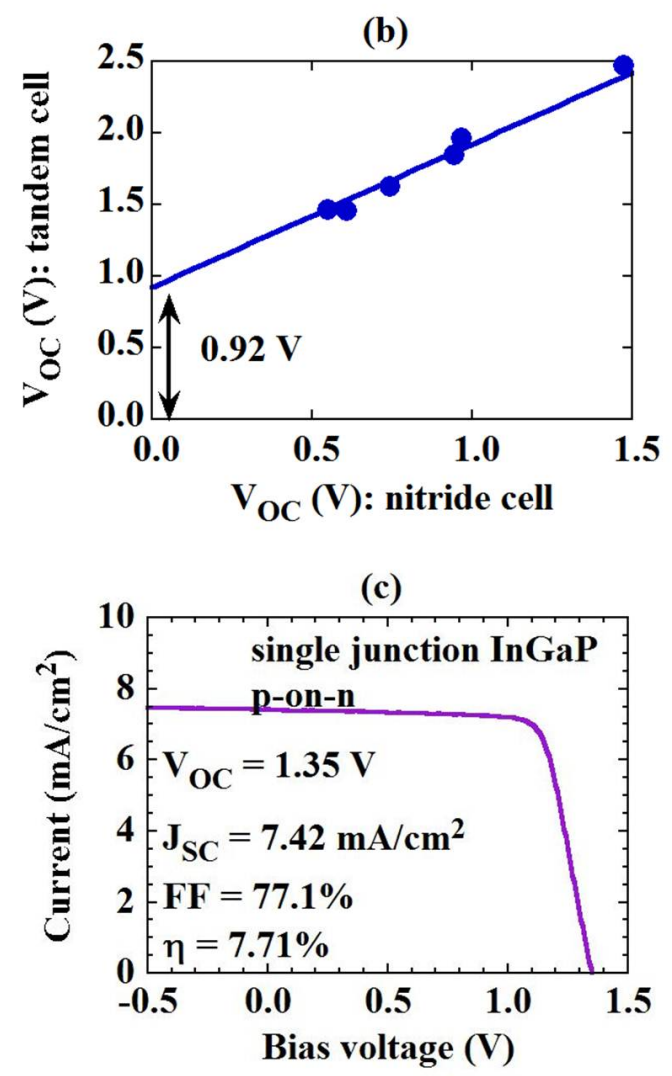

Fig. 3. (a) The $I-V$ characteristics of a nitride/InGaP tandem cell and the constituent nitride cell. Features of the nitride and tandem cells are tabulated. (b) The relationship between $V_{\mathrm{OC}}$ of tandem cells and that of nitride cells. (c) The $I-V$ characteristics of $p$-on- $n$ InGaP single junction cells.

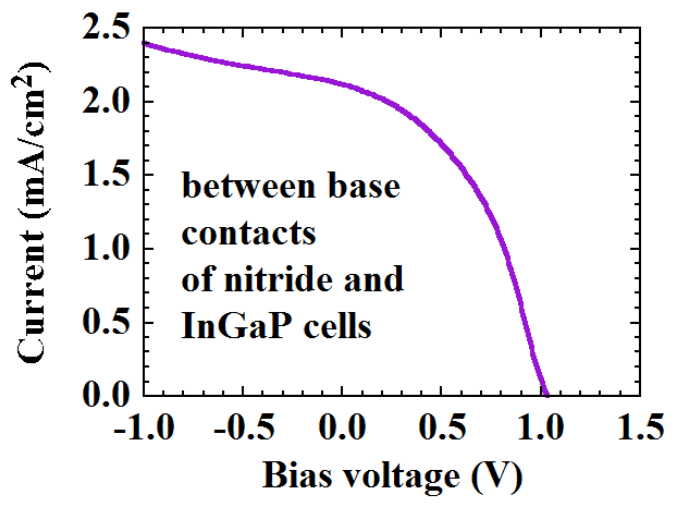

Fig. 4. The $I-V$ characteristics between the base contacts of nitride and phosphide cells with illumination.

$p$-GaAs $/ n$-GaN interface due to the valence band discontinuity between the two materials, which is assumed to be 1.6$1.7 \mathrm{eV}$ in the ideal junctions [22]. The performance of the tandem cells might be deteriorated by the potential barrier. The difference of the photocurrent flowing across the interface $\left(2.12 \mathrm{~mA} / \mathrm{cm}^{2}\right)$ from $J_{\mathrm{SC}}$ of the $\mathrm{InGaP}$ single junction cell $\left(7.42 \mathrm{~mA} / \mathrm{cm}^{2}\right)$ can be similarly explained.

In actual tandem cells, there could occur (i) the potential modulation due to the photo excited carriers in InGaP cells and (ii) the formation of the leak path across the bonding interface due to the bonding process [22]. The impact of the potential barrier is reduced in both schemes. The influence of the potential barrier is assumed to be further suppressed, for example, by employing $\mathrm{GaN}$ substrates with higher doping concentrations.

Anyhow given that the magnitude of the photocurrent across the bonding interface is larger than $J_{\mathrm{SC}}$ of the tandem cells by ten times, it is assumed that the electrical properties of the bonding interfaces do not cause serious effects on the characteristics of the nitride-on-phosphide tandem cells.

\section{CONCLUSION}

Using the surface-activated bonding in combination with the polishing of the bottom surfaces of GaN substrates, we successfully fabricated nitride/InGaP tandem solar cells. We found that $V_{\mathrm{OC}}$ was enhanced by stacking the two cells. We also found that the performance of the tandem cells was not seriously affected by the electrical characteristics of the GaN/GaAs bonding interfaces although a potential barrier was assumed to be formed there. These results suggest that the $\mathrm{SAB}$ is promising for fabricating nitride-on-phosphide subcell stacks, which are assumed to play an important role in realizing tandem cells of a larger number of subcells for higher efficiencies.

\section{ACKNOWLEDGEMENT}

The authors are grateful to L. Chai, M. Morimoto, and S. Nishida for their assistance in measurements. This work was supported by "Creative Research for Clean Energy Generation 
Using Solar Energy"project in Core Research for Evolutional Science and Technology (CREST) program of Japan Science and Technology Agency (JST).

\section{REFERENCES}

[1] L. L. Kazmerski, ftp://ftp2.nrel.gov/pub/ewckeei/Paper2_and_PPT2_Kazmerski_(final).pdf.

[2] T. Takamoto, E. Ikeda, and H. Kurita, "Over 30\% efficient InGaP/GaAs tandem solar cells", Appl. Phys. Lett. vol. 70, pp. 381-383, 1997.

[3] T. Takamoto, M. Kaneiwa, M. Imaizumi, and M. Yamaguchi, "InGaP/GaAs-based Multijunction Solar Cells", Prog. Photovolt: Res. Appl. vol. 13, pp. 495-511, 2005.

[4] J. F. Geisz, S. Kurtz, M. W. Wanlass, J. S. Ward, A. Duda, D. J. Friedman, J. M. Olson, W. E. McMahon, T. E. Moriarty, and J. T. Kiehl, "High-efficiency GaInP/GaAs/InGaAs triple-junction solar cells grown inverted with a metamorphic bottom junction", Appl. Phys. Lett. vol. 9, pp. 023502-1-023502-3, 2007.

[5] J. W. Ager III, L. A. Reichertz, K. M. Yu, W. J. Schaff, T. L. Williamson, M. A. Hoffbauer, N. M. Haegel, and W. Walukiewicz, "InGaN/Si heterojunction tandem solar cells", in Proc. 33rd IEEE Photovoltaic Specialists Conference, DOI: 10.1109/PVSC.2008.4922663, 2008.

[6] A. Yamamoto, K. Sugita, M. Horie, Y. Ohmura, M R. Islam, and A. Hashimoto, "Mg-doping and $\mathrm{n}^{+}-\mathrm{p}$ junction formation in MOVPEgrown $\operatorname{In}_{x} \mathrm{Ga}_{1-x} \mathrm{~N}(x \sim O .4)$ ), in Proc. 33rd IEEE Photovoltaic Specialists Conference, DOI: 10.1109/PVSC.2008.4922870, 2008.

[7] L. A. Reichertz, I. Gherasoiu, K. M. Yu, V. M. Kao, W. Walukiewicz, and J. W. Ager III, "Demonstration of a IIINitride/Silicon Tandem Solar Cell", Appl. Phys. Express, vol. 2, pp. 122202-1-122202-3, 2009.

[8] Y. Kuwahara, T. Fujii, T. Sugiyama, D. Iida, Y. Isobe, Y. Fujiyama, Y. Morita, M. Iwaya, T. Takeuchi, S. Kamiyama, I. Akasaki, and H. Amano, "Demonstration of a IIINitride/Silicon Tandem Solar Cell", Appl. Phys. Express, vol. 4, pp. 021001-1-021001-3, 2011.

[9] L. Sang, M. Liao, N. Ikeda, Y. Koide, and M. Sumiya, "Enhanced performance of InGaN solar cell by using a super-thin AlN interlayer", Appl. Phys. Lett. vol. 99, pp. 161109-1-161109-3, 2011.

[10] N. Watanabe, H. Yokoyama, N. Shigekawa, K. Sugita, and A. Yamamoto, "Barrier Thickness Dependence of Photovoltaic Characteristics of InGaN/GaN Multiple Quantum Well Solar Cells”, Jpn. J. Appl. Phys. vol. 51, pp. 10ND10-1-10ND10-5, 2012.

[11] A. G. Bhuiyan, A. Mihara, T. Esaki, K. Sugita, A. Hashimoto, A. Yamamoto, N. Watanabe, H. Yokoyama, and N. Shigekawa, "MOVPE growth of InGaN on $\mathrm{Si}(111)$ substrates with an intermediate range of In content", Phys. Status Solidi C, vol. 9, pp. 670-672, 2012.

[12] K. Tanabe, A. F. i. Morral, H. A. Atwater, D. J. Aiken, and M. W. Wanlass, "Direct-bonded GaAs/InGaAs tandem solar cell", Appl. Phys. Lett. vol. 89, pp. 102106-1-102106-3, 2006.

[13] M. J. Archer, D. C. Law, S. Mesropian, M. Haddad, C. M. Fetzer, A. C. Ackerman, C. Ladous, R. R. King, and H. A. Atwater, "GaInP/GaAs dual junction solar cells on Ge/Si epitaxial templates", Appl. Phys. Lett. vol. 92, pp. 103503-1-103503-3, 2008.

[14] H. Mizuno, K. Makita, and K. Matsubara, "Electrical and optical interconnection for mechanically stacked multi-junction solar cells mediated by metal nanoparticle arrays"Appl. Phys. Lett. vol. 101, 191111-1-191111-4, 2012.

[15] H. Takagi, K. Kikuchi, R. Maeda, T. R. Chung, and T. Suga, "Surface activated bonding of silicon wafers at room temperature", Appl. Phys. Lett. vol. 68, pp. 2222-2224, 1996.

[16] C. Wang, E. Higurashi, and T. Suga, "Void-Free Room-Temperature Silicon Wafer Direct Bonding Using Sequential Plasma Activation", Jpn. J. Appl. Phys. vol. 47, pp. 2526-2530, 2008.

[17] N. Shigekawa, N. Watanabe, and E. Higurashi, "Electrical Properties of Si-based Junctions by SAB", in Proc. 3rd Int. IEEE Workshop LowTemperature Bonding for 3D Integration, pp. 109-112, 2012.

[18] J. Liang, T. Miyazaki, M. Morimoto, S. Nishida, N. Watanabe, and N. Shigekawa, "Electrical Properties of p-Si/n-GaAs Heterojunctions by Using Surface-Activated Bonding", Appl. Phys. Express, vol. 6, pp. 021801-1-021801-3, 2013.

[19] J. Liang, S. Nishida, M. Morimoto and N. Shigekawa "SurfaceActivating-Bonding-Based Low-Resistance Si/III-V Junctions", accepted for publication in Elec. Lett.
[20] N. Shigekawa, J. Liang, N. Watanabe, and A. Yamamoto, "Fabrication of nitride/Si tandem cell structures with low environmental burden by surface activated bonding", to be presented in 10th International Conference on Nitride Semiconductors (ICNS-10), 2013.

[21] N. Watanabe, M. Mitsuhara, H. Yokoyama, J. Liang, and N. Shigekawa, "Well-number dependence of photovoltaic properties of InGaN/GaN multiple quantum well solar cells," presented in 40th Int. Symp. Comp. Semicond. (ISCS2013) TuA2-2, 2013.

[22] C. Lian, H. G. Xing, Y.-C. Chang, and N. Fichtenbaum, "Electrical transport properties of wafer-fused $\mathrm{p}-\mathrm{GaAs} / \mathrm{n}-\mathrm{GaN}$ ", Appl. Phys. Lett. vol. 93, pp. 112103-1-112103-3, 2008. 